\title{
Mechanisms of Dendritic Calcium Signaling in Fly Neurons
}

\author{
THOMAS G. OERTNER, TILMANN M. BROTZ, AND ALEXANDER BORST \\ Friedrich-Miescher-Laboratory of the Max-Planck-Society, D-72076 Tubingen, Germany
}

Received 27 June 2000; accepted in final form 15 September 2000

\begin{abstract}
Oertner, Thomas G., Tilmann M. Brotz, and Alexander Borst. Mechanisms of dendritic calcium signaling in fly neurons. J Neurophysiol 85: 439-447, 2001. We examined the mechanisms underlying dendritic calcium accumulation in lobula plate tangential cells of the fly visual system using an in vitro preparation of the fly brain. Local visual stimulation evokes a localized calcium signal in the dendrites of these cells in vivo. Here we show that a similar localized calcium accumulation can be elicited in vitro by focal iontophoretic application of the cholinergic agonist carbachol. The calcium signal had at least two sources: first, voltage-dependent calcium channels contributed to the carbachol-induced signal and were concentrated on the dendrite, the soma, and the terminal ramification of the axon. However, the dendritic calcium signal induced by carbachol stimulation was only weakly dependent on membrane depolarization. The most likely explanation for the second, voltage-independent part of the dendritic calcium signal is calcium entry through nicotinic acetylcholine receptors. We found no indication of second-messenger or calcium-mediated calcium release from intracellular stores. In summary, the characteristic spatiotemporal calcium signals in the dendrites of lobula plate tangential cells can be reproduced in vitro, and result from a combination of voltage- and ligand-gated calcium influx.
\end{abstract}

IN T R O D U C T I O N

Calcium can serve both as a charge carrier and a second messenger and therefore is able to link electrical activity to biochemical processes in nerve cells. Its functional role is best understood in presynaptic terminals where high local calcium concentrations are needed for the release of synaptic vesicles (Südhof 1995; Zucker 1996). The somatic calcium concentration influences the transcription of numerous genes (Hardingham et al. 1997). At the postsynaptic site, calcium is crucial for the induction of long-term changes in synaptic transmission (Bear and Malenka 1994; Eilers et al. 1996; Neveu and Zucker 1996; Tsumoto and Yasuda 1996). Dendrites can be hyperpolarized by the activation of $\mathrm{Ca}^{2+}$-dependent $\mathrm{K}^{+}$channels, effectively reducing the excitability of neurons (Sobel and Tank 1994). Calcium may play many other roles depending on the type of nerve cell where it occurs and exerts its action.

Calcium accumulation has been reported in vivo in fly lobula plate tangential cells (Borst and Egelhaaf 1992). The tangential cells represent a set of about 60 fairly large visual interneurons each of which can be identified individually due to their invariant anatomy and characteristic visual response properties (for review, see Hausen 1984). Located in the posterior part of the third visual neuropile of the fly, the lobula plate, they spatially pool the signals of thousands of local columnar ele-

Present address and address for reprint requests: T. G. Oertner, Cold Spring Harbor Laboratory, PO Box 100, 1 Bungtown Rd., Cold Spring Harbor, NY 11724 (E-mail: oertner@cshl.org). ments arranged in a retinotopic fashion (Haag et al. 1992). Tangential cells have large receptive fields and respond to visual motion in a directionally selective way (Borst and Egelhaaf 1990; Egelhaaf et al. 1989). There are cells tuned to horizontal motion, e.g., HS and CH cells (Eckert and Dvorak 1983; Hausen 1982a,b) and to vertical motion, e.g., VS cells (Hengstenberg 1982; Hengstenberg et al. 1982). The electrical response of many tangential cells consists of a graded shift in membrane potential, superimposed by irregular spikes in certain cell types (Haag and Borst 1996; Hengstenberg 1977). Excitatory and inhibitory synaptic input to the dendrites of VS and HS cells is mediated by nicotinic acetylcholine receptors and by $\mathrm{GABA}_{\mathrm{A}}$-like receptors, respectively (Brotz and Borst 1996).

The tangential cells are involved in the fly's visual course control system. Because of their well-established functional role, they serve as an attractive model for the analysis of single-cell computation (Single et al. 1997). With the aid of realistic compartmental models, the influence of anatomical and physiological features of the cell on its information processing capabilities can be explored (Borst and Haag 1996; Haag et al. 1997). Using this strategy, the functional role of fast $\mathrm{Na}^{+}$channels for the amplification of high-frequency synaptic input could be demonstrated (Haag and Borst 1996). Because of their position on the posterior surface of the brain and their flat, two-dimensional geometry, lobula plate tangential cells are easily accessible to imaging techniques. Stimulating the fly visually with gratings moving in the cell's preferred direction resulted in elevated calcium concentrations in the dendrite, the soma, and the terminal region of the axon (Borst and Egelhaaf 1992). Interestingly, the dendritic calcium signals were restricted to the stimulated branches of the dendritic arbor in a retinotopic fashion. To investigate the functional role of calcium in the dendrites of these cells, the mechanisms of calcium accumulation need to be clarified first. Here, we examine the sources of calcium accumulation in VS and $\mathrm{CH}$ cells in an in vitro preparation of the fly brain (Brotz et al. 1995) where the natural geometry and connectivity of the tangential cells are retained and extracellular ion and drug concentrations can be easily controlled.

\section{METHODS}

\section{Preparation and set-up}

The in vitro preparation of the blowfly brain has been described previously (Brotz et al. 1995). Briefly, female blowflies (Calliphora

\footnotetext{
The costs of publication of this article were defrayed in part by the payment of page charges. The article must therefore be hereby marked "advertisement" in accordance with 18 U.S.C. Section 1734 solely to indicate this fact.
} 
erythrocephala), 1-3 days old, were cold anesthetized and decapitated. The brain was removed under ice-cold saline by cutting the first optic chiasm between the lamina and the medulla and glued with its posterior surface onto a brass washer. The neurolemma of the anterior side was gently peeled off to ease the penetration with microelectrodes. The preparation was then transferred to the recording chamber where it was perfused with oxygenated fly saline $\left(95 \% \mathrm{O}_{2}-5 \% \mathrm{CO}_{2}\right.$, Messer Griesheim $\mathrm{GmbH}$, Germany) at a rate of $8 \mathrm{ml} / \mathrm{min}$. The recording chamber was mounted on an inverted microscope (Axiovert $35 \mathrm{M}$ with Plan-Neofluar $10 \times / 0.30$ Objective, Zeiss, Oberkochen, Germany). All experiments were performed at room temperature $\left(23-25^{\circ} \mathrm{C}\right)$

\section{Solutions}

As standard perfusion saline, we used a modified hemolymph-like solution after Stewart et al. (1994), composed of (in mM) $70 \mathrm{NaCl}, 5$ $\mathrm{KCl}, 1.5 \mathrm{CaCl}_{2}, 5 \mathrm{MgCl}_{2}, 10 \mathrm{NaHCO}_{3}, 5$ trehalose, 115 sucrose, and 5 HEPES, adjusted to pH 7.2 with $1 \mathrm{M} \mathrm{HCl}$. In low-Ca ${ }^{2+}$ saline, $\mathrm{CaCl}_{2}$ was replaced by $\mathrm{MgCl}_{2}$. In low- $\mathrm{Na}^{+}$saline, $\mathrm{NaCl}$ was replaced by $N$-methyl-D-glucamine $\left(\mathrm{NMDG}^{+}\right)$. To investigate the contribution from intracellular calcium stores to the calcium signals, ryanodine (10 $\mu \mathrm{M}$, Alomone Labs), thapsigargin ( $1 \mu \mathrm{M}$, Alomone Labs), or caffeine $(10 \mathrm{mM})$ was added to the perfusion solution. Chemicals were from Sigma unless otherwise noted.

\section{Recording of membrane potential}

Electrodes were pulled on a Brown-Flaming micropipette puller (P-97) using thin-walled glass capillaries with an outer diameter of 1 mm (GB100TF-10, Vitrex Modulohm, Herlev, Denmark). When filled with $500 \mathrm{mM} \mathrm{KCl}$ and $12 \mathrm{mM}$ fura-2 (Molecular Probes, Eugene, OR), electrodes had resistances of 80-110 M $\Omega$. Fura-2 was iontophoretically injected by applying negative current pulses of $1 \mathrm{nA}$ (1-Hz square wave, $50 \%$ duty cycle) for $3-5 \mathrm{~min}$. The membrane potential was recorded using an Axoclamp 2A amplifier (Axon Instruments, Foster City, CA). The headstage with the electrode holder was mounted on a stepmotor-driven micromanipulator (Luigs and Neumann, Ratingen, Germany). The output signal of the amplifier was digitized via a 12 bit A/D converter (CIO-DAS16F, Computerboards, Mansfield, MA) at a sampling rate of $10 \mathrm{~Hz}$ and fed into an Intel 486 based PC. The programs for data acquisition and evaluation were written in Turbo-Pascal (Borland).

\section{Optical recording and image processing}

Tangential cells stained with fura- 2 were illuminated by a monochromator (DeltaRAM, P. T. I., South Brunswick, NJ) via quartz fiber optics and imaged with a Peltier-cooled CCD-camera (CH250, Photometrics, Tucson, AZ). Images were acquired by an Apple Macintosh Quadra 900 and further processed with custom-written software in IDL (Research Systems, Boulder, CO). For ratiometric measurements (Grynkiewicz et al. 1985), 100 images were acquired at $1 \mathrm{~Hz}$ (binning factor, 2; exposure time, $500 \mathrm{~ms}$ ), alternating between 340 - and 380-nm excitation. To correct for spatial variation in the illumination, a thin film of fluorescein-solution under a coverslip was imaged at 340- and 380-nm excitation. The resulting correction images were low-pass filtered and normalized to their highest values, resulting in pixel values between 0.7 and 1 . The raw images of the cell at 340- and 380-nm illumination were divided pixel by pixel by the corresponding correction images to achieve a uniform background intensity. For evaluation, two different procedures were used: for a qualitative, image-based interpretation of the spatiotemporal changes, pairs of 340/380-nm images were divided pixel by pixel without background subtraction. Discarding the first image, the second 340/380 image of a sequence served as reference image and was subtracted on a pixelby-pixel basis from all the following ratio images. When viewed as a movie, the resulting stack of images gave an impression of the spatiotemporal changes in the 340/380-nm ratio. All false color images shown are based on this evaluation procedure, providing a qualitative representation of intracellular calcium changes. For quantitative analysis of $\left[\mathrm{Ca}^{2+}\right]_{\mathrm{i}}$, the background was subtracted in the raw images: The average pixel value of an unstained region of the tissue was determined for each image and subtracted from every pixel of that image. When the ratio 340/380 was calculated for a small region within the cell ( 10 pixels, $\approx 200 \mu \mathrm{m}^{2}$ ), care was taken not to include pixels outside the cell as these pixels are especially prone to noise. The resulting ratios were converted to absolute $\left[\mathrm{Ca}^{2+}\right]$ using a linear approximation of the calibration curve (fura- 2 calibration kit, Molecular Probes) between a ratio of $1\left(=100 \mathrm{nM} \mathrm{Ca}^{2+}\right)$ and $2(=400 \mathrm{nM}$ $\left.\mathrm{Ca}^{2+}\right)$ and plotted as a function of time.

\section{Pharmacological stimulation}

Cells were stimulated by iontophoretic application of the nonspecific cholinergic agonist carbachol. A Neurophore BH2 micro-iontophoresis system (Medical Systems, Greenvale, NJ) was connected to a low-resistance glass microelectrode $(10-20 \mathrm{M} \Omega$ ) filled with $0.1 \mathrm{M}$ carbachol. By means of a micromanipulator (Narishige, Japan), the electrode was inserted about $20 \mu \mathrm{m}$ into the tissue of the lobula plate at the ventrolateral margin of the neuropil. A retaining current of -10 nA was applied to prevent drug leakage. If not otherwise stated, the carbachol ejection current was adjusted between 20 and $100 \mathrm{nA}$ to depolarize the cell to $3-6 \mathrm{mV}$ from the resting potential.

\section{RES ULTS}

\section{General characteristics of electrical and calcium signal on carbachol stimulation}

In the intact fly, local visual stimulation leads to a depolarization and a localized calcium signal in the dendrite of tangential cells (Borst and Egelhaaf 1992). Here, we show that a similar localized dendritic calcium signal could be elicited in vitro by focal application of the cholinergic agonist carbachol. The general layout of the experiments is shown in Fig. 1A. A single tangential cell was filled with the calcium indicator fura-2 from a sharp intracellular electrode placed in the axon (Fig. 1B). This electrode was also used to monitor the membrane potential of the cell during the whole experiment. For stimulation, carbachol was released by iontophoresis from an extracellular microelectrode placed in the lobula plate. Images were taken at a rate of $1 \mathrm{~Hz}$, switching the excitation wavelength between 340 and $380 \mathrm{~nm}$. We observed a large change in the fluorescence ratio $8 \mathrm{~s}$ after the onset of a 1-s carbachol pulse (Fig. 1C). Warm colors encode large increases in the $340 / 380$ fluorescence ratio. The calcium signal was strongest in the dendrite close to the stimulation electrode (Fig. $1 C$, filled triangle). In addition, a weaker calcium signal was detectable in the terminal region of the axon (Fig. $1 C$, open triangle). There were no changes in fluorescence in the upper main branch of the dendrite or in the axon. The soma of the cell was not in the focal plane in this example. Figure $1 D$ shows the response to a weaker ejection current $(25 \mathrm{nA})$ at the same scaling. The amplitude of the signal is smaller and the spatial extension of the dendritic calcium accumulation is more restricted.

The time course of the dendritic calcium signal after background subtraction is shown in Fig. $2 A$. $\left[\mathrm{Ca}^{2+}\right]_{\mathrm{i}}$ rose about 50 $\mathrm{nM}$ above the resting value after the weak stimulation (grey squares) and about $160 \mathrm{nM}$ after the stronger stimulation (filled 

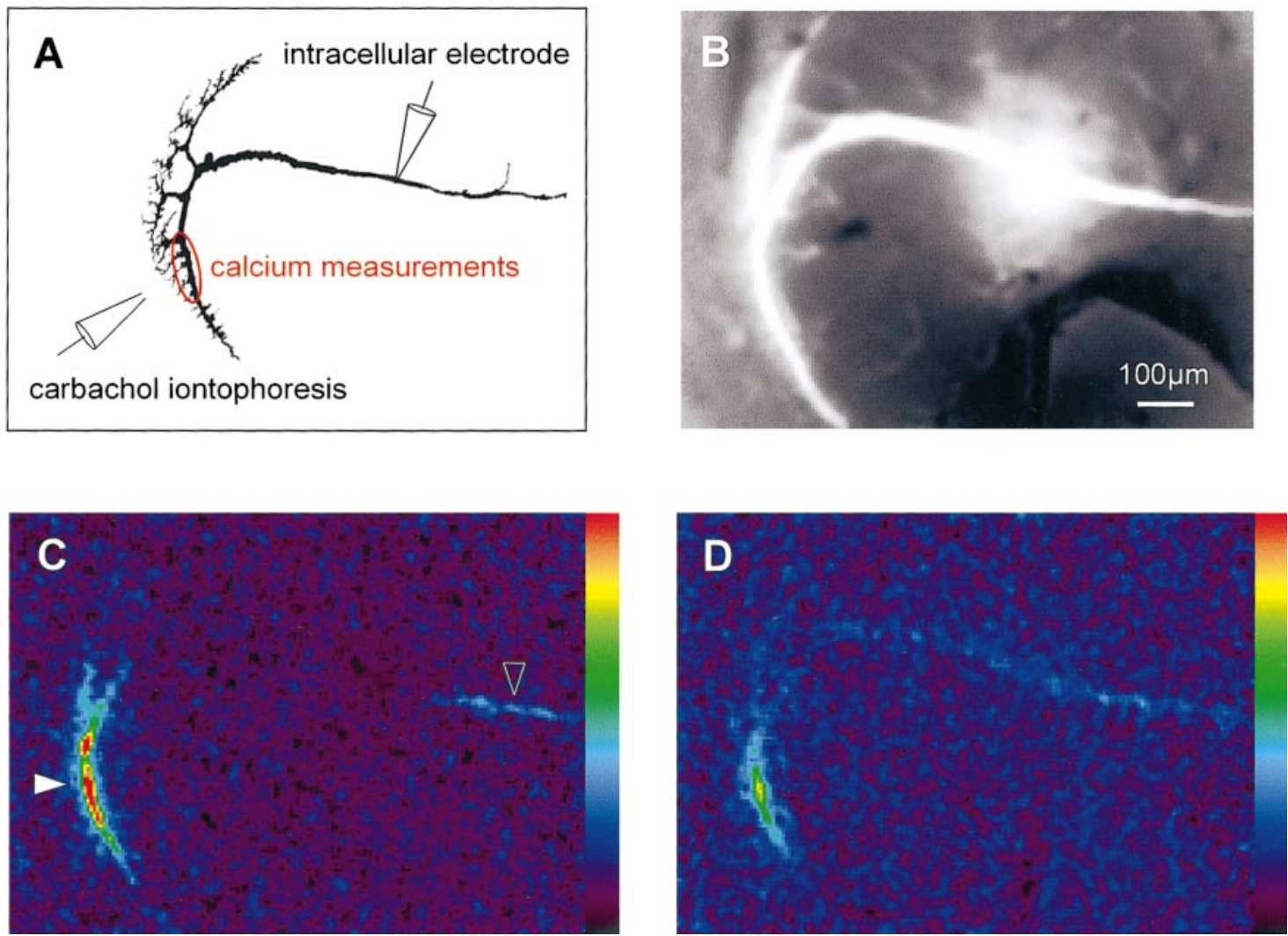

FIG. 1. Local carbachol application led to a spatially restricted dendritic calcium signal. A: spatial arrangement of iontophoresis electrode in the lobula plate and intracellular recording electrode in the axon of the VS cell. The changes in fluorescence were evaluated in the main dendrite (red circle). $B$ : raw fluorescence image of a VS2 cell filled with fura-2. The bright halo in the middle of the image results from the tip of the dye-filled intracellular electrode. The soma of the cell is not in the focal plane. $C$ : changes in the 340/380 nm ratio $8 \mathrm{~s}$ after the onset of a 1-s, 50-nA carbachol pulse. Note the strong dendritic signal and the weak signal in the terminal region of the axon. $D$ : changes in fluorescence ratio $8 \mathrm{~s}$ after a 1-s, 25-nA carbachol pulse. Intensity scaling of the images is identical in $C$ and $D$.

squares). The open squares correspond to the color coded images shown in Fig. $1, C$ and $D$. The peak $\left[\mathrm{Ca}^{2+}\right]_{\mathrm{i}}$ was reached 6-8 s after the onset of stimulation. Removal of free calcium was slow, with time constants of about 25-30 s. The onset of the voltage response as measured in the axon of these nonspiking cells was correlated with the calcium signal, but the rise time and decay were faster (Fig. $2 B$ ). After strong depolarizations, the time constant of repolarization was shortened and a slight afterhyperpolarization was often seen (black line). The amplitude of both depolarization and calcium signal were dependent on the carbachol dose. The dose-response curves of two different VS cells are given in Fig. 3, $A$ and $B$. Here, the ejection time was used to change the carbachol dose. The voltage response always saturated at lower doses than the local dendritic calcium signal. The fact that individual cells saturated at different carbachol doses is most likely due to the variable position of the stimulation electrode relative to the dendrite in each experiment. The sigmoid curve fitted to the calcium responses was shifted about $0.3 \log$ units to the right relative to the log dose-response curve of the voltage response, corresponding to a doubling of the carbachol dose necessary to reach the half-maximal response.

\section{Calcium enters the tangential cells from outside}

In principle, the observed elevation in $\left[\mathrm{Ca}^{2+}\right]_{\mathrm{i}}$ on cholinergic stimulation could arise from the influx of $\mathrm{Ca}^{2+}$ through chan-

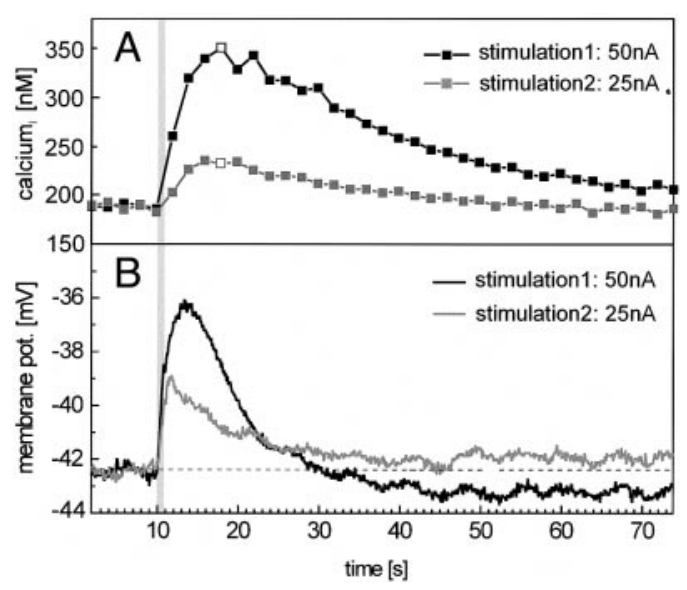

FIG. 2. Time course of calcium signal and depolarization of the cell shown in Fig. 1. $A$ : dendritic $\left[\mathrm{Ca}^{2+}\right]_{\mathrm{i}}$ after local dendritic stimulation by carbachol iontophoresis (gray bar). Responses to 2 different 1-s carbachol pulses are shown (50- and 25-nA iontophoresis current, respectively). The change in $\left[\mathrm{Ca}^{2+}\right]_{\mathrm{i}}$ was evaluated in the main dendritic branch close to the stimulation electrode as depicted in Fig. 1A. The open symbols correspond to the color coded images shown in Fig. 1, $C$ and $D$. B: the calcium signal was accompanied by a rapid depolarization of the cell. The large dose applied in stimulation 1 caused a strong depolarization followed by a weak afterhyperpolarization (black curve). This afterhyperpolarization was not seen after small carbachol doses (stimulation 2, gray curve). In this range of stimulation intensities the depolarization was approximately linear to the carbachol dose, while the calcium response was supralinear. 

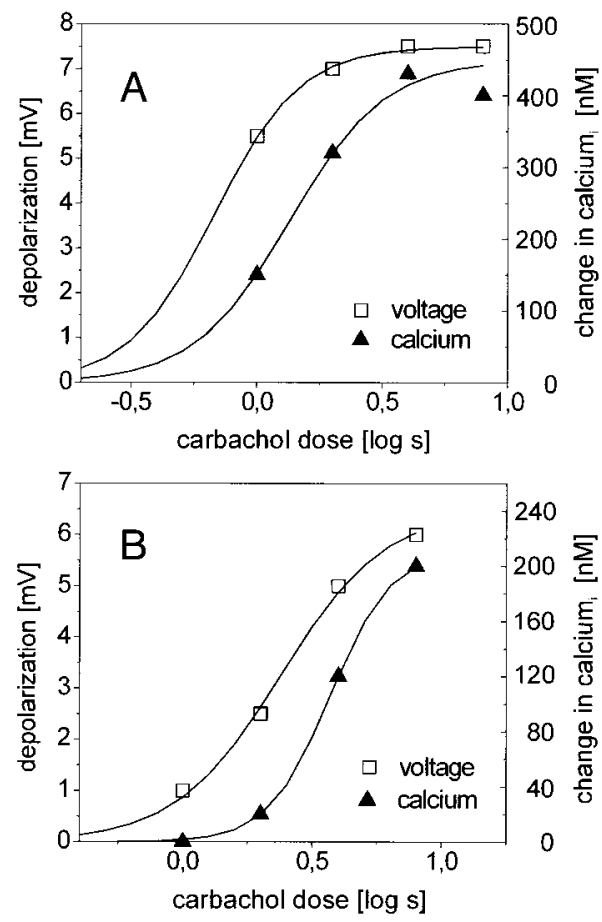

FIG. 3. Both peak voltage responses () and peak dendritic calcium signals (ム) were dependent on the carbachol dose given (2 VS2 cells). Carbachol was injected iontophoretically with a constant current of $100 \mathrm{nA}$ and injection times of $1,2,4$, and $8 \mathrm{~s}$, respectively. Although the elicited calcium transients varied in amplitude between individual cells, the electrical response always saturated at lower carbachol concentrations than the dendritic calcium transients.

nels in the plasma membrane, by calcium release from internal stores, or by a combination of both processes. To dissect these alternatives, we stimulated tangential cells after $10 \mathrm{~min}$ of perfusion with low-calcium saline. Calcium chelators were not added to prevent emptying of potential intracellular stores. Given the fact that the cells under scrutiny were still embedded in the tissue, we do not assume a complete washout of all extracellular $\mathrm{Ca}^{2+}$ ions under these conditions. Control values of the calcium response and depolarization were recorded in standard saline before and after low-calcium perfusion.
Figure 4 gives an example of one such experiment, together with average values. The placement of the electrodes is indicated on the photo of the dye-filled cell in Fig. 4A. After $10 \mathrm{~min}$ of perfusion with low-calcium saline, the calcium signal on carbachol stimulation was completely abolished in this experiment (Fig. 4F). Response amplitudes across experiments were normalized to the respective control responses. In low-calcium saline, the calcium signal was on average reduced to $21 \%$ of the control experiments (Fig. $4 D, n=3$ ). This reduction was completely reversible after switching back to standard saline. From this we conclude that the observed calcium signal is caused primarily by an influx of $\mathrm{Ca}^{2+}$ from the extracellular space. There are two more features in the responses which deserve closer inspection. 1) Resting values of $\left[\mathrm{Ca}^{2+}\right]_{i}$ were lower in low-calcium saline, suggesting a permanent influx of $\mathrm{Ca}^{2+}$ ions under control conditions. Experiments in vivo corroborate a constant calcium influx in the absence of stimulation (Haag and Borst 2000). 2) Examining the electrical response of the cell, we found that the depolarization in low- $\mathrm{Ca}^{2+}$ saline was on average $13 \%$ stronger than under control conditions (Fig. 4D). The electrical response was more strongly enhanced in low-calcium experiments with virtually abolished calcium responses than in low-calcium experiments with residual calcium responses. The most likely explanation for the weaker depolarization in the control experiment is a $\mathrm{K}^{+}$current activated by elevated $\left[\mathrm{Ca}^{2+}\right]_{\mathrm{i}}$. This current would limit the depolarization after calcium influx and could also account for the afterhyperpolarization seen after strong depolarizations (Fig. 2).

The absence of a $\mathrm{Ca}^{2+}$ signal in low-calcium saline is in accordance with a purely nicotinic pharmacology of the acetylcholine receptors (AChRs). Inositol 1,4,5-triphosphate $\left(\mathrm{IP}_{3}\right)$-mediated $\mathrm{Ca}^{2+}$ release from internal stores triggered by muscarinic AChRs would be independent of the extracellular $\mathrm{Ca}^{2+}$ concentration. This is in line with a previous pharmacological study in which muscarinic antagonists were unable to block carbachol-induced depolarization and muscarinic agonists did not lead to a depolarization of tangential cells (Brotz and Borst 1996). The possibility of an additional contribution by calcium-induced calcium release (CICR) from internal cal-
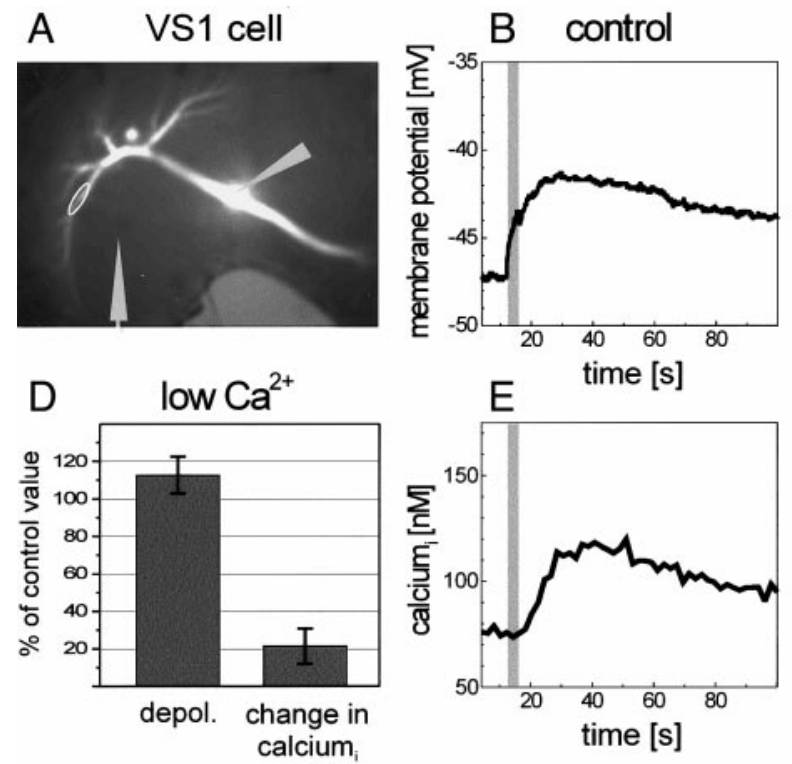
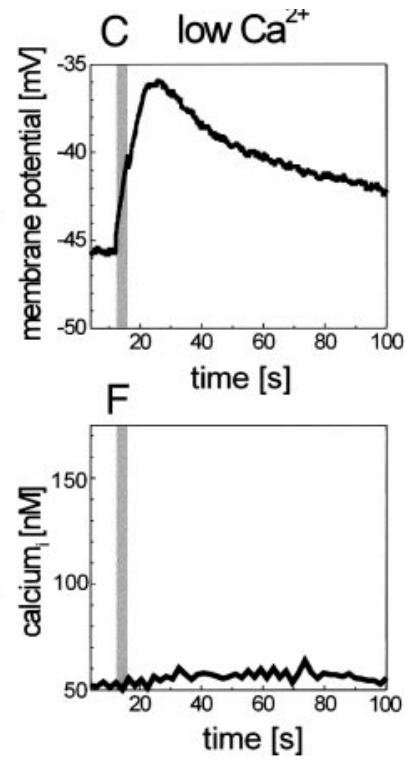

FIG. 4. The calcium signal was dependent on extracellular $\left[\mathrm{Ca}^{2+}\right]$. $A$ : raw fluorescence image of a VS1 cell filled with fura-2. The positions of stimulating and recording electrode are indicated by white arrows. Changes in $\left[\mathrm{Ca}^{2+}\right]_{\mathrm{i}}$ were evaluated in the encircled part of the dendrite. $B$ : electrical response to carbachol stimulation (gray bar) in standard saline. $C$ : in low-calcium saline, the electrical response was increased. $D$ : summary of experiments on 3 different VS cells (1VS1, 2 VS2). For each cell, the amplitude of electrical and calcium signal in low-calcium saline was normalized to the average amplitude of the control responses in standard saline (before and after low-calcium perfusion). Bars show the normalized average responses in low-calcium saline $\pm \mathrm{SE}$. The depolarization was increased to $112 \%$ on average, whereas the calcium response was reduced to about $21 \%$ of the control experiments. $E$ : dendritic calcium signal after carbachol stimulation in standard saline. $F$ : in low calcium saline, the dendritic calcium signal was strongly reduced. 
cium stores cannot be excluded by low-calcium experiments but has to be addressed by use of specific pharmacological tools (see following text).

\section{Internal calcium stores could not be activated}

Influx of calcium ions could, in principle, trigger calciuminduced calcium release from intracellular stores by activation of ryanodine receptors. To trigger the release of calcium from putative intracelluar stores, we perfused the preparation with saline containing $10 \mu \mathrm{M}$ ryanodine for $5 \mathrm{~min}$, then stimulated presumptive ryanodine receptors by bath application of caffeine $(10 \mathrm{mM}, 2 \mathrm{~min})$. During the caffeine application, $\left[\mathrm{Ca}^{2+}\right]_{\mathrm{i}}$ was monitored. For these experiments, VS and HS cells were used. We found no change in $\left[\mathrm{Ca}^{2+}\right]_{\mathrm{i}}$ using this paradigm $(n=$ $5)$ or by applying caffeine alone $(n=4)$. In a second set of experiments, we tested the effects of thapsigargin, a potent blocker of sarco/endoplasmic reticulum $\mathrm{Ca}^{2+}$-ATPase (SERCA) (Jackson et al. 1988). Bath application of $1 \mu \mathrm{M}$ thapsigargin for $10 \mathrm{~min}$ did not trigger calcium release in unstimulated cells $(n=8)$ nor did it reduce carbachol-induced calcium responses (Fig. 5). We therefore conclude that intracellular stores do not significantly contribute to the evoked calcium transients in these cells.

Calcium influx through voltage-dependent calcium channels (VDCCs)

The experiments in low-calcium saline described in the preceding text indicate a contribution of extracellular $\mathrm{Ca}^{2+}$ to
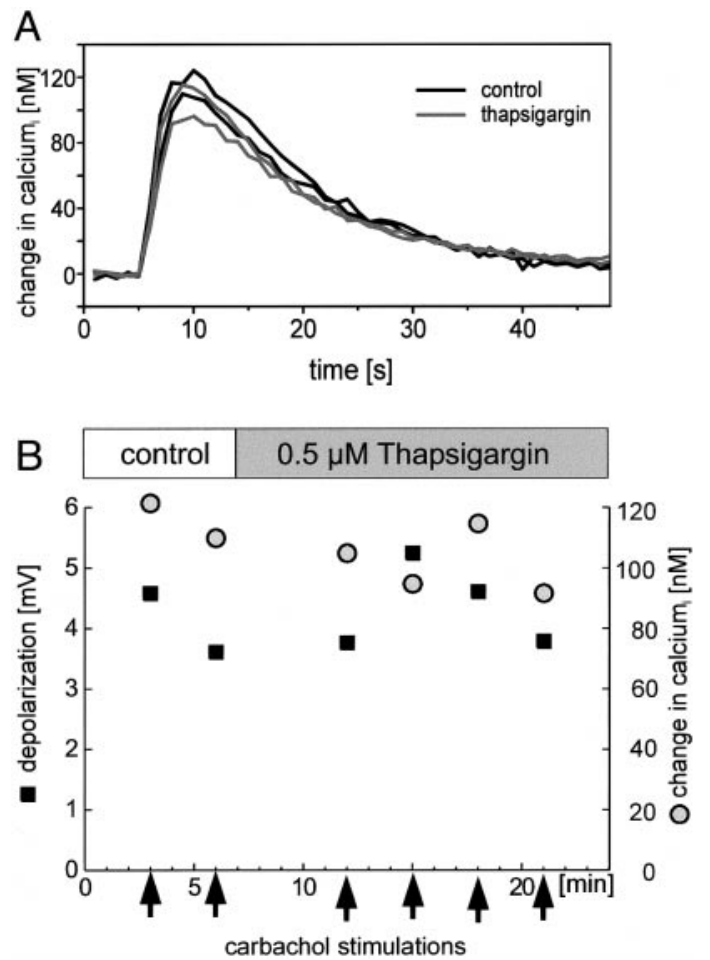

FIG. 5. Thapsigargin did not alter the calcium signal on carbachol stimulation (VS3 cell). A: time course of dendritic calcium signals in standard saline (black curves) and after 8 and 11 min of perfusion in saline containing $0.5 \mu \mathrm{M}$ thapsigargin (gray curves). $B$ : the peak amplitude of the electrical responses (squares) and the increase in dendritic $\left[\mathrm{Ca}^{2+}\right]_{\mathrm{i}}$ (circles) are shown in 2 control stimulations, and after bath application of $0.5 \mu \mathrm{M}$ thapsigargin for $5,8,11$, and $14 \mathrm{~min}$. There was no significant decline of the average calcium response or of the average electrical response. the calcium signal in tangential cells. However, since stimulation of nAChRs by carbachol led to a depolarization of the cells, influx through nAChRs and through VDCCs could not be discriminated in these experiments. To examine voltage-dependent calcium influx in isolation, we manipulated the cell's membrane potential by current injection instead of carbachol iontophoresis. In $\mathrm{CH}$ cells, depolarizing current injections of 10 and $15 \mathrm{nA}$ into the axon caused a strong increase in $\left[\mathrm{Ca}^{2+}\right]_{\mathrm{i}}$ in the dendritic arborizations in the lobula plate and in the protocerebrum (Fig. $6 \mathrm{C}$ ). The calcium influx into the axon and primary dendritic branches was much smaller and reached its peak several seconds after the termination of the current injection (Fig. 6D, blue curve). This delayed signal in the main dendritic branches and the axon was most probably caused by calcium diffusion from smaller branches of the dendrite. If the voltage-gated calcium influx in these experiments was due to the activation of VDCCs, they are not distributed homogeneously across the membrane, but concentrated on the dendritic branches of higher order. In VS1 cells, depolarizing current injections also caused a strong dendritic calcium influx $(n=2)$, whereas in VS2 and VS3 cells the dendritic calcium signal was weak or absent ( $n=5$, data not shown).

To exclude the possibility of calcium influx through the sodium-calcium exchanger operating in reverse mode (Hoyt et al. 1998), we analyzed the influence of the extracellular sodium concentration on the calcium signal induced by depolarizing current injections. After wash-in of low- $\mathrm{Na}^{+}$saline, resting $\left[\mathrm{Ca}^{2+}\right]_{\mathrm{i}}$ rose about $30-50 \mathrm{nM}$ above the resting level in standard saline. This effect was reversed after washing with standard saline. For better comparison of the time courses, the calcium transients in Fig. 7 are shown relative to resting $\left[\mathrm{Ca}^{2+}\right]_{\mathrm{i}}$ before the stimulation. In low- $\mathrm{Na}^{+}$saline, the peak calcium influx during the depolarizations was unchanged, but the time constant of calcium removal was prolonged. This effect was reversible after perfusion in standard saline. From this we conclude that the calcium influx during depolarizations was caused mainly by the activation of VDCCs and not by the sodium-calcium exchanger operating in reverse mode. The slow return to resting calcium levels hints to the importance of the sodium-calcium exchanger for the fast removal of calcium ions from the cytoplasm.

\section{Calcium influx through nicotinic AChRs}

To demonstrate $\mathrm{Ca}^{2+}$ influx through nicotinic AChRs (nAChRs), we tried to prevent the cell from depolarizing on carbachol stimulation. Because of the high impedance of the recording electrode and the large size of the cells, conditions were unfavorable for reliable voltage-clamp experiments. By replacing extracellular $\mathrm{Na}^{+}$with $\mathrm{NMDG}^{+}$, reducing $\left[\mathrm{Na}^{+}\right]_{\mathrm{o}}$ from 80 to $10 \mathrm{mM}$, we could prevent the fast depolarization on carbachol stimulation (Fig. 8C). Under these conditions, the rise in dendritic $\left[\mathrm{Ca}^{2+}\right]_{\mathrm{i}}$ was very similar to the control experiment during the first $20 \mathrm{~s}$ after carbachol stimulation (Fig. $8 F$ ). In the next $60 \mathrm{~s}$, the calcium levels returned to baseline in the control experiments but continued to rise in the low- $\mathrm{Na}^{+}$ saline. On average, the depolarization was reduced to about $26 \%$ of the control responses, but the dendritic calcium signal still reached $87 \%$ of the control amplitude (Fig. $8 D, n=3$ ). Measurements were taken at the time of peak depolarization in the control experiments (15 s after stimulus onset). From this 

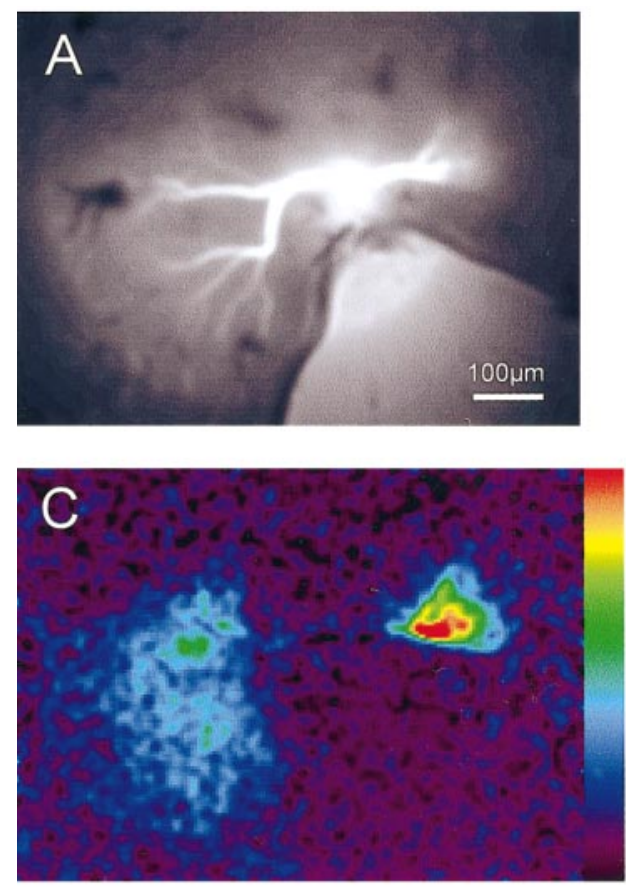
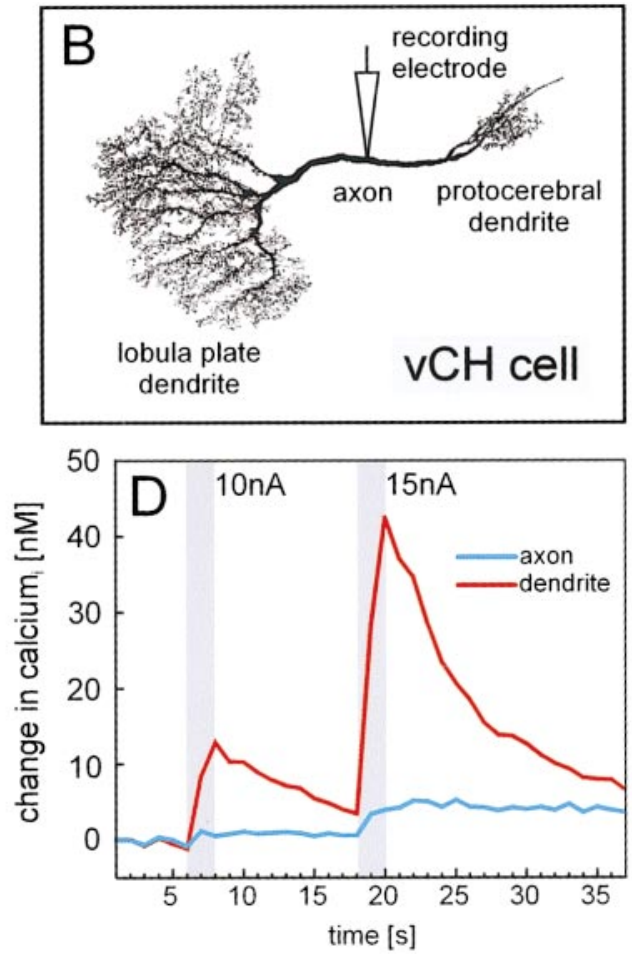

FIG. 6. Changes in calcium after depolarizing current injections into the axon of a $\mathrm{vCH}$ cell. $A$ : raw fluorescence image of a $\mathrm{vCH}$ cell filled with fura-2. $B$ : schematic of $\mathrm{vCH}$ cell showing the 2 dendritic arborizations in the lobula plate (left) and in the protocerebrum (right). The soma of this cell is located in the contralateral side of the brain. $C$ : injection of $+15 \mathrm{nA}$ for $2 \mathrm{~s}$ caused an increase in $\left[\mathrm{Ca}^{2+}\right]_{i}$ in the dendritic arborizations in the lobula plate and in the protocerebrum. Note the absence of a calcium signal along the axon and in the main branches of the dendrite. $D$ : average time course of calcium signal in the axon (blue) and protocerebral dendrite (red, $n=8 \mathrm{vCH}$ cells). The gray bars show the duration of 2 current injections of +10 and $+15 \mathrm{nA}$, respectively. we conclude that under control conditions, the fast depolarization was carried mainly by $\mathrm{Na}^{+}$ions, under control conditions, $\mathrm{Ca}^{2+}$ entered the cell mainly through ligand-gated channels, and removal of $\mathrm{Ca}^{2+}$ is dependent on the function of the $\mathrm{Na}^{+} / \mathrm{Ca}^{2+}$ exchanger. These experiments suggest a small contribution of VDCCs to the bulk calcium signal, which seems to consist mainly of voltage-independent calcium influx. This is in accordance with experiments in which the effect of simultaneous hyperpolarizing current injection on the carbacholinduced calcium transients was examined (data not shown). In these experiments, hyperpolarization of VS and HS cells could

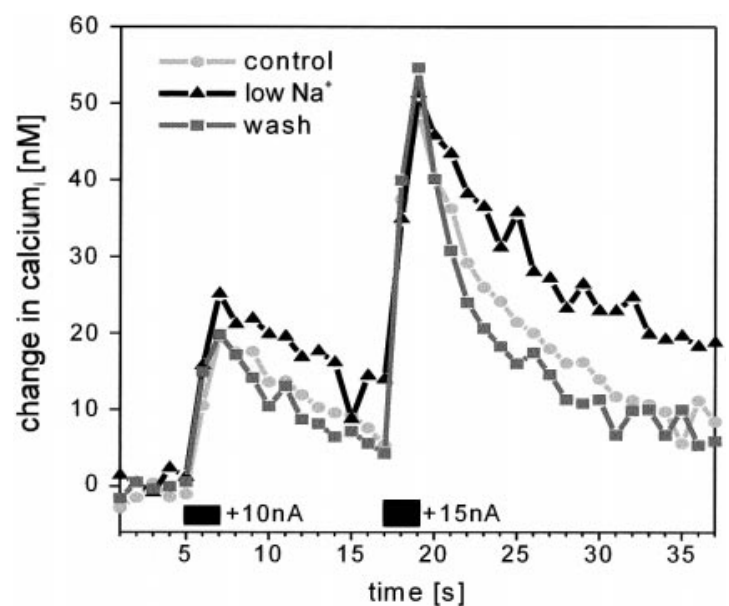

FIG. 7. The increase in $\left[\mathrm{Ca}^{2+}\right]_{\mathrm{i}}$ after depolarizing current injections was not dependent on extracellular $\left[\mathrm{Na}^{+}\right]$. In this experiment on a VS2 cell, changes in $\left[\mathrm{Ca}^{2+}\right]_{\mathrm{i}}$ in response to current injections of +10 and $+15 \mathrm{nA}$ are shown. The same amplitude was reached in the control experiment in standard saline (O), in low- $\mathrm{Na}^{+}$saline $(\mathbf{\Delta})$, and after 5 min wash in standard saline ( $\square$ ). The extrusion of $\mathrm{Ca}^{2+}$ from the cytoplasm, however, was delayed in low- $\mathrm{Na}^{+}$ saline. not prevent dendritic calcium influx after carbachol stimulation.

\section{I S C U S S I O N}

Focal application of the cholinergic agonist carbachol in vitro led to a localized dendritic calcium signal in the dendrites of tangential cells. In principle, this calcium signal could be caused by calcium influx through ligand- or voltage-gated channels or by calcium release from internal calcium stores. Reducing the extracellular calcium concentration strongly attenuated the carbachol-induced calcium signal (Fig. 4), demonstrating an influx of calcium ions from the extracellular space. CICR could, in principle, amplify this initial calcium influx. However, stimulation of putative ryanodine receptors did not change the intracellular calcium concentration. Blocking calcium pumps on the endoplasmic reticulum with thapsigargin did not evoke calcium transients nor did it reduce the amplitude of carbachol-induced calcium transients (Fig. 5). From this we conclude that CICR does not contribute significantly to the carbachol-evoked calcium transients in these cells.

We also considered the possibility of $\mathrm{IP}_{3}$-mediated calcium release from intracellular calcium stores, triggered by the stimulation of muscarinic receptors. In cockroach motoneurons, for example, the stimulation of muscarinic receptors is known to activate calcium release (David and Pitman 1996). However, second-messenger-mediated calcium release from internal stores is not dependent on calcium influx from the extracellular space and should be strongly influenced by blocking calcium pumps of the endoplasmic reticulum. Exactly the opposite was found in the experiments reported here, making a muscarinic mechanism in tangential cells highly unlikely. This corroborates a previous electrophysiological study of fly tangential 

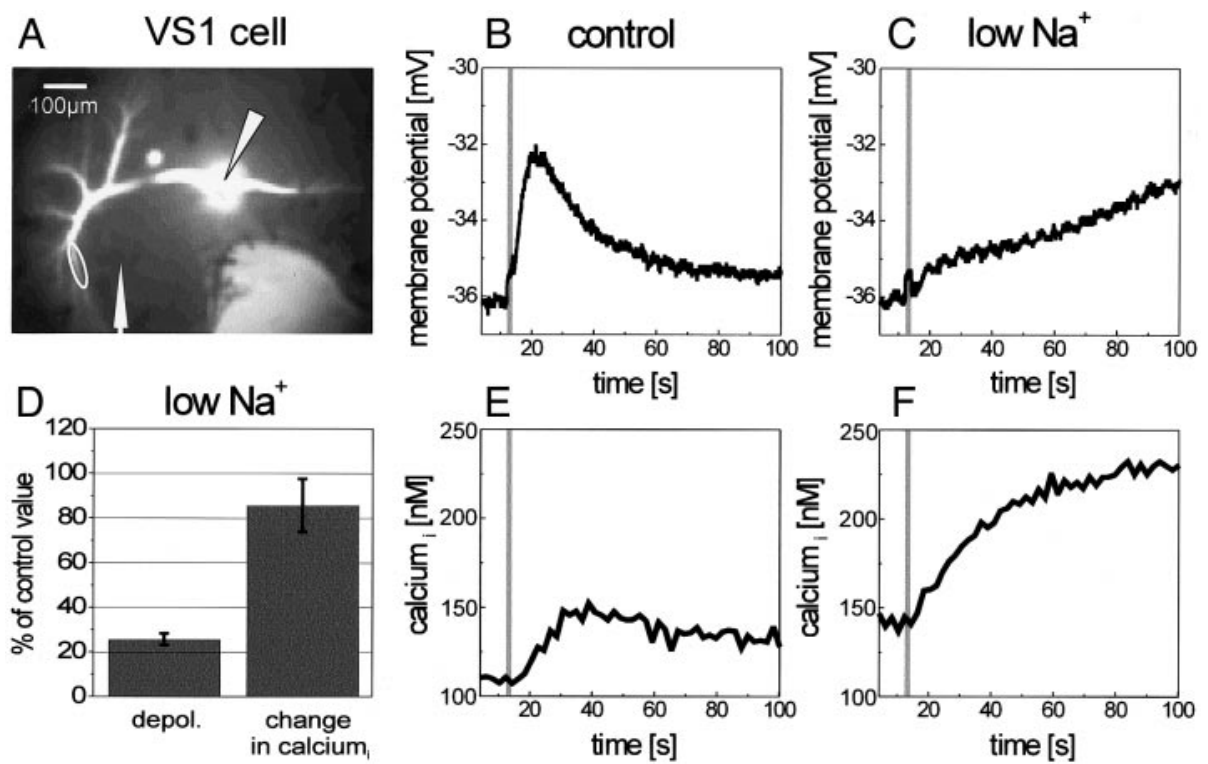

FIG. 8. The dendritic calcium signal was not dependent on fast membrane depolarization. A: raw fluorescence image of a VS1 cell. White arrows indicate positions of iontophoresis electrode and recording electrode in the axon (scale bar $=100 \mu \mathrm{m}$ ). $B$ : in standard saline, the cell shown in $A$ depolarized in response to a carbachol pulse (gray bar). $C$ : in low- $\mathrm{Na}^{+}$saline, the initial fast depolarization was prevented. Instead, there was a slow depolarization over the course of several minutes. The resting potential was reached only after switching back to standard saline. $D$ : summary of low- $\mathrm{Na}^{+}$experiments on 3 different VS cells. Measurements were taken $15 \mathrm{~s}$ after stimulus onset, coincident with the maximal depolarization in the control experiments. The responses in low- $\mathrm{Na}^{+}$saline were normalized to the control responses before averaging. Error bars show SE. In low- $\mathrm{Na}^{+}$saline, the depolarization after carbachol stimulation was reduced on average to about $26 \%$, whereas the dendritic calcium signal still reached $87 \%$ of the control responses. $E$ : dendritic calcium signal in standard saline. $F$ : in low- $\mathrm{Na}^{+}$saline, the increase in dendritic $\left[\mathrm{Ca}^{2+}\right]_{\mathrm{i}}$ in the first $20 \mathrm{~s}$ after the onset of stimulation was similar to the control experiment as shown in $E$. In contrast to the control experiment, the elevation in $\left[\mathrm{Ca}^{2+}\right]_{\mathrm{i}}$ was not terminated, indicating that calcium removal mechanisms were affected by the reduction in $\left[\mathrm{Na}^{+}\right]_{\mathrm{o}}$. Note also the elevated resting $\left[\mathrm{Ca}^{2+}\right]_{\mathrm{i}}$ in low-Na ${ }^{+}$saline.

cells, where the pharmacology of AChRs has been characterized as being nicotinic (Brotz and Borst 1996).

The dendritic voltage-gated calcium influx demonstrated here in vitro (Fig. 6) has been characterized by voltage-clamp experiments in vivo (Haag and Borst 2000). It is activated over a broad range of membrane potentials between -60 and -20 $\mathrm{mV}$ in a fairly linear fashion. This unusual characteristic has led to speculations whether the voltage-gated influx is due to the activation of voltage-gated calcium channels or caused by the sodium-calcium exchanger operating in reverse mode. Due to the stochiometry of the exchanger ( 3 sodium ions are extruded for 1 calcium ion to enter), calcium influx through the exchanger would be accompanied by a net outward current (Blaustein and Lederer 1999). This, however, is inconsistent with the electrophysiological characterization of calcium currents in $\mathrm{CH}$ cells: the cobalt-sensitive current remaining after blocking voltage-gated $\mathrm{K}^{+}$and $\mathrm{Na}^{+}$channels is an inward current (Haag et al. 1997). A second argument against calcium influx through the exchanger comes from the experiments reported here, where replacing extracellular sodium ions by $\mathrm{NMDG}^{+}$did not reduce the amplitude of the calcium signals (Fig. 7). We conclude that the depolarization-induced calcium influx is indeed due to the activation of low-threshold voltagegated calcium channels. At the resting potential of about -50 $\mathrm{mV}$, this current will be partially activated, leading to a balance between permanent calcium influx and energy-consuming removal by calcium pumps and sodium-calcium exchangers. Although sodium-calcium exchangers do not consume ATP themselves, they are driven by the sodium gradient established by ATPases. It comes as no surprise that these graded-response neurons employ different mechanisms of calcium homoeostasis than the more extensively studied spiking neurons: a persistent calcium current would provide a mechanism for encoding continuous voltage changes in both depolarizing and hyperpolarizing directions.

In the experiments in low-sodium saline, resting $\left[\mathrm{Ca}^{2+}\right]_{\mathrm{i}}$ was elevated and the return of $\left[\mathrm{Ca}^{2+}\right]_{i}$ to resting values after short depolarizing current injections was prolonged (Fig. 7). If the cell was stimulated with carbachol under these conditions, it was literally flooded with calcium (Fig. 8F). Even after switching back to standard saline, $\left[\mathrm{Ca}^{2+}\right]_{i}$ remained elevated for several minutes. These conditions were clearly deleterious for the cells as the responses to control stimulations in standard saline were strongly reduced after extended periods of elevated $\left[\mathrm{Ca}^{2+}\right]_{\mathrm{i}}$ (data not shown). The prolonged depolarization seen after carbachol stimulation in low- $\mathrm{Na}^{+}$saline might be partly caused by presynaptic cells: since the calcium metabolism is affected in all cells in the tissue, a carbachol pulse might lead to extensive transmitter release due to elevated calcium levels in presynaptic terminals. If only the cell under scrutiny was depolarized by a short current injection in low-sodium saline, $\left[\mathrm{Ca}^{2+}\right]_{i}$ slowly returned to baseline after $1-2$ min (Fig. 7). These observations, together with the elevated resting calcium levels seen in low- $\mathrm{Na}^{+}$saline, are in accordance with the sodium-calcium exchanger mainly mediating $\left[\mathrm{Ca}^{2+}\right]_{\mathrm{i}}$ recovery after carbachol stimulation. However, since removal of extracellular sodium ions affects all exchange mechanisms that rely on the sodium gradient, more complicated interactions are possible (Storozhevykh et al. 1998). In the tangential cells, the transport capacity of ATP-dependent calcium pumps alone 
seems to be insufficient to restore resting calcium levels while the cell is depolarized.

In vertebrate neurons, calcium influx through nAChRs can contribute significantly to changes in postsynaptic calcium concentration (Mulle et al. 1992; Vernino et al. 1994). For insect CNS neurons, there are only few studies of the calcium fluxes through nAChRs. A study on cultured Kenyon cells of the bee reports a calcium-to-sodium permeability ratio of 6.4 (Goldberg et al. 1999). In cultured neurons from embryonic cockroach brains, calcium influx through nAChRs was below detection threshold (van Eyseren et al. 1998). In experiments on isolated somata from locust thoracic ganglia, the influx associated with the opening of nAChRs contributed about $25 \%$ to the total calcium signal after carbachol stimulation (Oertner et al. 1999). However, these results cannot be transferred to lobula plate tangential cells because the relative density of nAChRs and VDCCs might strongly vary in different kinds of neurons. In the dendrites of fly tangential cells, the experiments in low- $\mathrm{Na}^{+}$saline reported here suggest a large contribution of ligand-gated calcium influx. Qualitatively the permeability of dendritic nAChRs for calcium is supported by a series of calcium measurements in tangential cells in vivo. Lack of congruence between membrane potential and calcium signal was first described in HS cells during visual motion stimulation at high temporal frequencies (Egelhaaf and Borst 1995). Under these conditions, the membrane potential as measured in the axon was unchanged from rest after an initial transient, but the dendritic calcium signal was large and continued to rise after the membrane potential had returned to rest. This suggests a voltage-independent component of the visually induced calcium signal. In experiments on VS cells, a rise in $\left[\mathrm{Ca}^{2+}\right]_{\mathrm{i}}$ was observed in the fine terminal branches of the dendrite during visual stimulation against the preferred direction in spite of a general hyperpolarization of the cell (Borst and Single 2000). Since both excitatory and inhibitory inputs become activated during visual stimulation against the preferred direction (Single et al. 1997), the observed rise in $\left[\mathrm{Ca}^{2+}\right]_{\mathrm{i}}$ can be readily explained by calcium influx through nAChRs.

Low- $\mathrm{Na}^{+}$saline reduced the carbachol-induced dendritic calcium signals to about $87 \%$ of the control responses (Fig. $8 D$ ). The electrical responses were more strongly reduced to about $26 \%$ of the controls. Assuming that the voltage-gated calcium influx is proportional to the depolarization, it follows that under control conditions only about $18 \%$ of the total calcium signal was dependent on membrane depolarization. This is in contrast to the above-mentioned in vivo experiments, which concluded that on visual stimulation, the majority of the dendritic calcium signal is due to influx through VDCCs (Borst and Single 2000; Single and Borst 1998). First, injection of a hyperpolarizing current during visual stimulation strongly reduced the pattern-induced calcium modulations in the dendrite (Single and Borst 1998). Second, model calculations based on the relative amount of dendritic calcium elicited during preferred versus nonpreferred motion stimulation concluded that about $60 \%$ of the total calcium accumulation during preferred direction motion is due to influx through VDCCs (Borst and Single 2000). How can this discrepancy be explained? Unlike acetylcholine, carbachol is not degraded by cholinesterases in the tissue. Application of carbachol will therefore activate AChRs more extensively and with a prolonged time course compared with synaptic stimulation in vivo. Considering the sensitivity of VDCCs to changes in the intracellular calcium and ATP concentration (Hao et al. 1999), it is also possible that during the preparation procedure a large fraction of VDCCs had been lost or inactivated. This would shift the balance toward the more robust ligand-gated calcium entry. The larger depolarizing currents needed to elicit a calcium influx in vitro support this explanation. Therefore the particular relation of voltage- to ligand-gated calcium influx found in the experiments reported here cannot be transferred uncritically to the situation in vivo.

The functional role of dendritic calcium in the tangential cells remains to be investigated. The afterhyperpolarization seen after strong depolarization (Fig. 2) and the enhanced electrical response in low-calcium experiments with virtually abolished calcium responses (Fig. 4) suggest a calcium-activated $\mathrm{K}^{+}$current in the dendrites of VS cells. This could also account for the fact that strong carbachol stimulations saturated the voltage response while the calcium response still increased (Fig. 3). A positive correlation between the calcium influx and the size of the afterhyperpolarization has also been reported in HS cells in experiments with visual stimulation in vivo (Kurtz et al. 1999). A calcium-mediated inhibitory mechanism could provide local adaptation within a single cell due to the local restriction of the calcium signals to the stimulated regions of the dendrite. Because of the slow time constant of calcium removal, the internal calcium concentration provides a temporal average of the local excitatory input. Up to now, local adaptation to visual motion stimulation (Maddess and Laughlin 1985) has always been attributed to neuronal circuits presynaptic to the tangential cells. The possibility of calcium-dependent local adaptation within the dendrite of single tangential cells is intriguing and will be addressed in subsequent studies.

We are grateful to K. Götz from the Max-Planck-Institute of Biological Cybernetics in Tübingen for generous loan of part of the equipment, to T. Martin for excellent technical assistance, and to J. Haag and K. Zito for critically reading the manuscript.

Present addresses: T. M. Brotz, National Cancer Institute, Experimental Immunology Branch, 10 Center Dr., Bethesda, MD 20892-1360; A. Borst, Department of Environmental Science, Policy, and Management, Division of Insect Biology, University of California, 201 Wellman Hall, Berkeley, CA 94720-3112.

\section{REFERENCES}

Bear MF and MalenKa RC. Synaptic plasticity: LTP and LTD. Curr Opin Neurobiol 4: 389-399, 1994.

Blaustein MP AND LeDERER WJ. Sodium-calcium exchange: its physiological implications. Physiol Rev 79: 763-854, 1999.

Borst A AND EgelhaAf M. Direction selectivity of fly motion-sensitive neurons is computed in a two-stage process. Proc Natl Acad Sci USA 87: 9363-9367, 1990.

BORST A AND EGELHAAF M. In vivo imaging of calcium accumulation in fly interneurons as elicited by visual motion stimulation. Proc Natl Acad Sci USA 89: 4139-4143, 1992.

BORST A AND HAAG J. The intrinsic electrophysiological characteristics of fly lobula plate tangential cells. I. Passive membrane properties. J Computat Neurosci 3: 313-336, 1996.

BORST A AND Single S. Local current spread in electrically compact neurons of the fly. Neurosci Lett 285: 123-126, 2000.

BRotz TM AND Borst A. Cholinergic and GABAergic receptors on fly tangential cells and their role in visual motion detection. J Neurophysiol 76: 1786-1799, 1996.

Brotz TM, EgelhaAf M, AND Borst A. A preparation of the blowfly (Calliphora erythrocephala) brain for in vitro electrophysiological and pharmacological studies. J Neurosci Methods 57: 37-46, 1995. 
DAVID JA AND PITMAn RM. Muscarinic receptor activation modulates ligandgated ion channels in an insect motorneuron via changes in intracellular calcium. Proc R Soc Lond B Biol Sci 263: 469-474, 1996.

ECKERT H AND DVORAK DR. The centrifugal horizontal cells in the lobula plate of the blowfly Phaenicia sericata. J Insect Physiol 29: 547-560, 1983.

EGELHAAF M AND BORST A. Calcium accumulation in visual interneurons of the fly: stimulus dependence and relationship to membrane potential. $\mathrm{J} \mathrm{Neu}$ rophysiol 73: 2540-2552, 1995.

EgelHAAF M, Borst A, AND REICHARDT W. Computational structure of a biological motion detection system as revealed by local detector analysis in the fly's nervous system. J Opt Soc Am A 6: 1070-1087, 1989.

EIlers J, Plant T, and KonNerth A. Localized calcium signalling and neuronal integration in cerebellar Purkinje neurones. Cell Calcium 20: 215-226, 1996

Goldberg F, Grünewald B, Rosenboom H, and Menzel R. Nicotinic acetylcholine currents of cultured Kenyon cells from the mushroom bodies of the honey bee Apis mellifera. J Physiol (Lond) 514: 759-768, 1999.

Grynkiewicz G, Poenie M, and Tsien RY. A new generation of $\mathrm{Ca}^{2+}$ indicators with greatly improved fluorescence properties. J Biol Chem 260: 3440-3450, 1985.

HAAG J AND BoRsT A. Amplification of high-frequency synaptic inputs by active dendritic membrane processes. Nature 379: 639-641, 1996.

HAAG J AND BORST A. Spatial distribution and characteristics of voltage-gated calcium currents within visual interneurons. J Neurophysiol 83: 1039-1051, 2000.

HaAg J, EgelhaAf M, and Borst A. Dendritic integration of motion information in visual interneurons of the blowfly. Neurosci Lett 140: 173-176, 1992.

HaAg J, Theunissen F, AND Borst A. The intrinsic electrophysiological characteristics of fly lobula plate tangential cells. II. Active membrane properties. J Computat Neurosci 4: 349-368, 1997.

Hao LY, Kameyama A, and KameYama M. A cytoplasmic factor, calpastatin and ATP together reverse run-down of $\mathrm{Ca}^{2+}$ channel activity in guinea-pig heart. J Physiol (Lond) 514: 687-699, 1999.

Hardingham GE, Chawla S, Johnson CM, and Bading H. Distinct functions of nuclear and cytoplasmic calcium in the control of gene expression. Nature 385: 260-265, 1997.

HAUSEN K. Motion sensitive interneurons in the optomotor system of the fly. I. The horizontal cells: structure and signals. Biol Cybern 45: 143-156, 1982a.

HAUSEN K. Motion sensitive interneurons in the optomotor system of the fly. II. The horizontal cells: receptive field organization and response characteristics. Biol Cybern 46: 67-79, 1982b.

HAUSEN K. The lobula-complex of the fly: structure, function and significance in visual behaviour. In: Photoreception and Vision in Invertebrates, edited by Ali MA. New York: Plenum, 1984, p. 523-559.

HeNGSTENBERG R. Spike response of "non-spiking" visual interneurone. $\mathrm{Na}$ ture 270: 338-340, 1977.

HENGSTENBERG R. Common visual response properties of giant vertical cells in the lobula plate of the blowfly Calliphora. J Comp Physiol [A] 149: 179-193, 1982.
Hengstenberg R, Hausen K, and Hengstenberg B. The number and structure of giant vertical cells (VS) in the lobula plate of the blowfly Calliphora erythrocephala. J Comp Physiol [A] 149: 163-177, 1982.

Hoyt KH, ARden SR, Aizenman E, and Reynolds IJ. Reverse $\mathrm{Na}^{+} / \mathrm{Ca}^{2+}$ exchange contributes to glutamate-induced intracellular $\mathrm{Ca}^{2+}$ concentration increases in cultured rat forebrain neurons. Mol Pharmacol 53: 742-749, 1998.

JACKSON TR, PATTERSON SI, THASTRUP O, AND HANLEy MR. A novel tumor promoter, thapsigargin, transiently increases cytoplasmic free $\mathrm{Ca}^{2+}$ without generation of inositol phosphates in NG115-401L neuronal cells. Biochem J 253: 81-86, 1988 .

KURTZ R, DÜRR V, AND EgelHAAF M. On the function of local $\mathrm{Ca}^{2+}$ signals in visual motion sensitive neurons of the blowfly. In: Proceedings of the 27th Göttingen Neurobiology Conference, edited by Elsner N and Eysel U. Stuttgart: Thieme, 1999, vol. II, p. 445.

MAdDESS T AND LAUGHLIN SB. Adaptation of the motion-sensitive neuron H1 is generated locally and governed by contrast frequency. Proc $R$ Soc Lond B Biol Sci 225: 251-275, 1985.

Mulle C, Choquet D, Korn H, and Changeux J-P. Calcium influx through nicotinic receptor in rat central neurons: its relevance to cellular regulation. Neuron 8: 135-143, 1992.

Neveu D and ZuCKeR RS. Postsynaptic levels of $\left[\mathrm{Ca}^{2+}\right]_{\mathrm{i}}$ needed to trigger LTD and LTP. Neuron 16: 619-629, 1996.

OERTNER TG, Single S, AND Borst A. Separation of voltage- and ligand-gated calcium influx in locust neurons by optical imaging. Neurosci Lett 274: 95-98, 1999 .

Single S AND Borst A. Dendritic integration and its role in computing image velocity. Science 281: 1848-1850, 1998.

Single S, HAAG J, AND BorST A. Dendritic computation of direction selectivity and gain control in fly visual interneurons. J Neurosci 17: 6023-6030, 1997.

SOBEL EC AND TANK DW. In vivo $\mathrm{Ca}^{2+}$ dynamics in a cricket auditory neuron: an example of chemical computation. Science 263: 823-826, 1994.

Stewart BA, Atwood HL, Renger JJ, Wang J, AND Wu CF. Improved stability of Drosophila larval neuromuscular preparations in hemolymphlike physiological solutions. J Comp Physiol [A] 175: 179-191, 1994.

Storozhevykh T, Grigortsevich N, Sorokina E, Vinskaya N, Vergun O, Pinelis V, AND KHODOROV B. Role of $\mathrm{Na}^{+} / \mathrm{Ca}^{2+}$ exchange in regulation of neuronal $\mathrm{Ca}^{2+}$ homeostasis requires re-evaluation. FEBS Lett 431: 215-218, 1998.

SüDHOF TC. The synaptic vesicle cycle: a cascade of protein-protein interactions. Nature 375: 645-653, 1995.

Tsumoto T AND YASUDA H. A switching role of postsynaptic calcium in the induction of long-term potentiation or long-term depression in visual cortex. Semin Neurosci 8: 311-319, 1996.

van Eyseren I, Tiaho F, Guen JL, Guillet JC, and Pichon Y. Effects of nicotinic and muscarinic ligands on embryonic neurones of Periplaneta americana in primary culture: a whole cell clamp study. J Insect Physiol 44: 227-240, 1998.

VERNINO S, ROGERS M, RADCLIFFE KA, AND DANI JA. Quantitative measurement of calcium flux through muscle and neuronal nicotinic acetylcholine receptors. J Neurosci 14: 5514-5524, 1994.

ZUCKER RS. Exocytosis: a molecular and physiological perspective. Neuron 17: 1049-1055, 1996 